\title{
REDEFINING THE MANAGEMENT OF PERFORMANCE ORIENTATION IN THE ROMANIAN HIGHER EDUCATIONAL SYSTEM
}

\author{
Andy Pușcă ${ }^{1}$, Ionel Sergiu Pîrju ${ }^{2}$
}

\begin{abstract}
Education is the best investment in the future of a nation. This article reviews the Romanian educational system and offers insights into the issues surrounding the performance orientation of the universities in the context of recent transformations after the ingression in the European Union. Our intention through this article is to present solutions for the improvement of performance orientation in the Romanian educational system. We will analyze the situation of higher education in Romania as: regional performance of the universities, which is a direct result of national literacy rate, the enrolment rate of the youth, the governmental funds etc. The contemporary Romanian educational system is focused on the development of a performed management style in synergy with the European educational strategy. The article presents the issues related to the national higher education performance and its strategic role for enhancing the excellence of a sustainable economy. The prospects of the Romanian performance orientation are discussed from a synchronic point of view.
\end{abstract}

JEL Classification Number: A20, DOI: 10.12955/cbup.v7.1371

Keywords: Romanian, education, university, performance, management, reform

\section{Introduction}

Romania, as a former socialist nation, has experienced one of the hardest transitions from totalitarianism to the market economy, compared to other communist states such as: Poland, the Czech Republic or Hungary. Uncertainty, political chaos and economic decline have been present in the educational process because the political leadership manifested in many cases irresponsibility and indifference.

The reforms inside the higher education system are competence-oriented changes and represent new ways in improving the performance in South Eastern Europe in a new context of political and economic transformation generated by the transition from communism to democracy. Changes and managerial reforms are being developed at a slower pace compared to the European Union (EU) vision. The marginalized position is attributed to the reduced importance for higher educational developments (Webster, 2011) which are providing limited opportunities for the shareholders in the context of slow reform initiatives in this state.

The aspiration of the Romanian educational system is to share the same values as the rest of the South Eastern European countries regardless of EU membership. The reconstitution of the academic curricula, the new systems of accreditation for the universities, the proposal of new skills for a knowledge-based society are new international tools used for the improvement of the quality of education (Tatto \& Mincu, 2009).

The purpose of this study is to explore the management of performance orientation in the Romanian educational system in order to better understand the factors which influence skill development in students. The Romanian educational system is seen in this article as attempting to construct a new national strategy based on the acceptance of European values which is continuously struggling to achieve better performance orientation. The identified issues include: the presentation of the Romanian educational situation, a general overview of the national universities and the analyses of performance orientation in the context of regional society.

Under the aegis of the European Union, the aim of the Romanian educational system is to harness major cross-national priorities: intelligent development of the long live learning process as a base for regional competitiveness. There is a provocation for Romania to adopt in short term a competitive and innovative European policy, because the nation is "provoked" by international partners to promote the acceptance of performance orientation as a basis for increasing the role of equalitarian values. In Romania there is a need for performance orientation related to the improvement of the educational system and the promotion of competitive management. The process of education can be studied by focusing on the performance strategy as a base for achieving excellency in the professional life of citizens. In order to understand some aspects of reduced performance orientation in the educational process we will analyze the principles, the present reality and the strategies for improving the contemporary situation.

\footnotetext{
${ }^{1}$ Danubius University, Galați, Romania, andypusca@univ-danubius.ro

${ }^{2}$ Danubius University, Galați, Romania, pirjusergiu@univ-danubius.ro
} 


\section{The contemporary education system in Romania}

Acceptance into the European Union was for Romania the premise for the development of an egalitarian and performance orientated state. The emerging economy is constantly trying to create a new path of development in the global society, even the European institutions are having great difficulty in projecting democratic values and ethical forms of capitalism into an inhospitable terrain (Gallagher, 2009).

At present, the official policy of Romania is based on semi presidential doctrine (Crowther, 2010) and the unitary state, even it is consolidated, has a limited influence in controlling the success of the economy. The same situations are identified in the national educational management of higher education where the goal is to transfer Western concepts to regional context without deformation of the process.

The share of females in Romanian population was in 1960-2016 on average of 50.99\%, greater than the world average of $49.74 \%$. However, the population growth in the same time frame was on average of $0.13 \%$, smaller than the world average of $1.6 \%$. The urban population of $54 \%$ is greater than the world average of $42 \%$, and the international rank is among the $56 \%$ of the World (Romanian census, 2011) but is decreasing in the last years as a result of aggressive emigration of the work force. Romania is an equalitarian nation with a flexible position regarding the independence of women and their involvement in important aspects of political life. The literacy rate between 1992-2011 ranks between the first $17 \%$ in the World (Ioan, 2018). The presence of women in high levels of the educational hierarchy is not limited and they play important roles as professors and scholars both in private or public institutions.

Primary school enrolment is situated on the first $92 \%$ in the World. The same index mentioned above presents the enrolment in secondary education among the first $57 \%$ in the World and for the tertiary is among the first $48 \%$ in the World. The intention is to contribute to the citizens welfare and education is seen as an attempt to moderate the uncertainty of life by assuming entrepreneurial risks in the future.

The governmental implication in spending public money for education in the last 20 years is on average $7 \%$, which is smaller than the World average investments in this sector, of around $14 \%$. For general expenditure per children Romania ranks among first $65 \%$ in the World while for tertiary students its rank is among $70 \%$ in the World (Gender Equality Index, 2017).

In regard to compulsory education in Romania, we can say that it is extended by 10 years under the premises of European strategy. In the communism era (1945-1989) the educational system was developed as an intention to build up a high-quality country capable to face the provocation of the west. The present strategy can be described as moderate in performance orientation especially in rural areas. There are some international performances as Romania placed 5th in the International Mathematical Olympiad with 316 medals, from 1959, after China, Russia Federation, United States and Hungary. Dating back from 1989 Romania ranks the 6th place at the International Olympiad in Informatics (Business Review, 2014).

The new vision after the EU integration demands for the teachers a set of reforms based on the decentralization of education, diversification of the values (Pantic, 2012) and multiple other transitions capable of changing for the better the performance of the system. The sustainability of the educational system is based on the European Union developement strategy for 2020:

1. Smart growth based on supporting knowledge and innovation.

2. Sustainable growth: supporting a competitive economy and ecology.

3. Inclusive economy, centered on social inclusion and territorial cooperation (Europa.eu, 2019).

The teachers will have a central role in the solidification of these activities, and they will help in increasing the employment, $75 \%$ of the population aged between 20 and-64 years should have a job, and the reduction of early school leavings must be under $10 \%$. For these objectives, $2.3 \%$ of the European GDP should be invested in research and developments projects and at least $40 \%$ of the younger generation should have a tertiary degree.

The allocation of $2 \%$ from the national GDP for research and development is very difficult in Romania because this sector is rudimental in most of the domains, except the IT industry. In 2010 the spending for research was $0.30 \%$ from the national budged, compared to Finland where the investments reached $4 \%$ of their GDP (European Institute in Romania, 2019). Obtaining tertiary degrees for $40 \%$ of the young generation aged bellow 30 years demands a strong reformation of the educational system and real 
investments in the professional training of teachers. The young generation of Romanian scholars is not satisfied with the performance of the national research system and wish that the strategy be planned more carefully in a more caring academic space.

We believe that the Romanian institutional education can improve its concern for fairness and the optimization of personal and collective performance offers collectivistic solutions to the regional problems. A major transformation in terms of performance will put emphasis on practical solutions aiming to realize the manageable aspects of the European directive related to education.

\section{A synchronic overview of the higher educational system}

After the Romanian integration into European structures, education has become organized following the uniformity of the Bologna system. As in many parts of the world, education has its national specificity and is interconnected with political and economic management. Cross-cultural education, especially in universities, is seen as an incentive to reach various socio-cultural goals (Zait, 2002) and represents a pillar from the Eastern European multiculturality.

Romanian society is based on feminine values with social and emotional implications (Hofstede \& Hofstede, 2005), and cultural superiority it is not accepted, even the culture is learned from social groups. In schools and universities, we can find a real gender equality and the social role for managerial positions are not determined by gender constraints. The participation of women is very common in top management; the current Minister of Education is a woman, there is no gender segregation and differences in earnings and professional status are illegal. As a rule, in Romania we cannot find important fluctuations based on gender, religion or minority, but the cultural factors affect the entrepreneurial behavior (Gasse \& Tremblay, 2011) and public pressure is accepted by the educational leaders. In this culture a university degree is seen as equally important for the career evolution of women and men alike.

The educational curriculum is founded on European principles, the preservation of national identity is realized in the same way for Romanians and for the minorities who are living in Romania. The main problems are the political differences which are undesirable realities for achieving long-term performance. In the past, the educational system has been linked to assertive communist principles (Tonnies, 2017) without greater liberty of choices and the mainstream tendency was to create university graduates according to the dominant soviet model.

The Romanian higher educational system is part of the Central Eastern European cluster which has not been a top performer in the last three decades, even it is evolving under the European Union curricula. According to the Ranking Web of Central Eastern European Universities (2019) the high number of universities from the regional top 100 are in Poland (26), Russia (21) and the Czech Republic (14). In Romania there are 7 universities in this classification and in the rest of the countries the number is below 5 from each state.

The universities are relatively new and have been influenced by the Austrian and German model in Transylvania and by the French methodology in Wallachia and Moldavia, the historical provinces of Romania.

The oldest University in Romania is Alexandru Ioan Cuza from Iasi, founded in 1860 by the state decree of the first modern national prince, Alexandru Ioan Cuza. It was converted from a former educational institution, Academia Mihaileana, a landmark of national education, into a modern university which now is offering study programs in Romanian, English, French and German (UAIC, 2019).

The international recognition of Romanian universities was systemized in the Table 1.

\begin{tabular}{|c|c|c|c|c|c|}
\hline Name & Regional rank & World rank & Presence rank & Impact & Excellence \\
\hline University Babes Bolyai & 37 & 892 & 1063 & 1226 & 949 \\
\hline University of Bucharest & 43 & 1043 & 1857 & 1393 & 1126 \\
\hline A.I. Cuza University & 56 & 1236 & 1669 & 1419 & 1430 \\
\hline West University & 73 & 1527 & 3399 & 2919 & 1299 \\
\hline Technical University Cluj Napoca & 84 & 1664 & 2270 & 2768 & 1648 \\
\hline G. Asachi Technical University & 88 & 1688 & 2694 & 2729 & 1717 \\
\hline Academy of Economic Studies & 98 & 1801 & 1599 & 1154 & 2692 \\
\hline
\end{tabular}


The number of students decreased recently having reached almost 539, 000 persons in the $2017-2018$ academic year. The highest percentage of the students are prefer careers in law and business (24\%) and only $21 \%$ are prefer engineering related specializations (Romania Insider, 2018).

The number of private schools and kinder gardens is increasing, but the number of private universities is dwindling. This situation is a consequence of the of the fact that state universities are very well protected by the authorities- free of tuition. Another aspect is the economic uncertainty and the political lack of performance, which cause a large number of young persons to leave the county in searching for a better life abroad. The desideratum in Romanian universities is to achieve democracy, an equality in a society based on European principles and to stop political connections in the promotion of the educational leaders.

Romania is a high context culture with national minorities and common educational projects which open the possibility for collective action, helping the development of an equalitarian society where the professional status can be achieved only by competent persons.

\section{Performance orientation in the educational management}

At present the Romanian educational system is perceived to be in crisis and attracts waves of criticism and challenges. After the Romanian revolution in 1989, education has been under many restrictions and reforms and every new Government was centered on political struggles (Papadimitriou\& Phinnemore,2008) and not on managerial achievements capable to promote meritocracy and not the social stratification.

In some institutions the educational society is still influenced by the traditional features of the totalitarian heritage of the 20-th century, and unfortunately the transitional period after the 1990s was not capable of creating the best educational standards.

There are cases, especially in national universities with high influence in their geographic proximity, where the overwhelming amount of resources for research are under the control of small groups of political monopolistic coalitions. We can still find educational managers, mostly politically elected, who are motivated by a combination between state-run bureaucratic supervision and the lack of social responsibility, with no human values and beliefs.

There is low performance orientation in the system because there is a reduced extend to which leaders and top members of organizations (in this case universities) are encourage and reward the group members for performance and excellence (House et al., 2004; Chhokar et al. 2008).

Educational careers are not always a stimulus for the best professionals because the relatively low wages in Romania compared to other countries are below the expectations of top scholars.

In the context of a knowledge-based society, Romania does not having a tradition in the management of lifelong learning like the Scandinavian states. In the Nordic cluster the prevalent Protestant work ethic have nourished lifelong learning and according to Sjovaag \& Bergmann (2012) an equalitarian system is helping employees to become more performance oriented within a collective system.

After the admission into EU, the institutional context of educational management has changed in some aspects, and private investors removed a small part of the crucial monopoly and ownership of the state in this sector. The new private educational centers (universities, high schools, vocational institutions etc.) are creating short-term performances and are better centered on the values of stakeholders. The Romanian state as a traditional shareholder still represent the main force, but the innovative ideas in achieving the performance are constantly evolving as an adaptive response to the European educational environment. The Romanian scholars are not spending as much time in national and international conferences and even the number of MBAs is growing, the costs are huge for the majority of interested people.

Despite these new transformations, uncertainty avoidance is still present in the national mentality. According to Hofstede \& Hofstede (2005) Romania has a high score of this dimension - 90 compared to Latin America and new African democracies. The collectives are avoiding uncertainty by relaying on social norms, arrangements and bureaucratic practices, as part of their strategy to alleviate possible unpleasant future events. In the contact with the public officials, individual people do not have equal status and the top functions in the higher educational system are mostly segregated in accordance to the directives of the dominant political parties. 
Romanian students are eager to achieve progressiveness, a search for the new improvement of personal performance and are adapted to the European environment. We identify two major tendencies in the Romanian academic system where some authorial practices from the past are combined with the democratic principles of the EU:

1. Even the educational management is excellent in theory, in many cases is unproper put in practice.

2. The performance orientation is mainly based on European development programs such as Erasmus and through them the universities are supporting and encouraging formal and informal learning.

As a concrete recommendation, the best form in supporting the sustainable progress of a national educational system is the adequate management of performance in the lifelong learning process.

The pillars of criticism are mostly based on extensive and in many cases inutile curricula, the bureaucracy and the lack of equality on the national employment market. In our opinion, to enhance performance orientation, there is a need for a decentralization of the educational system. As part of the EU, Romania is committed to support the Union in the global competition for being the best provider of education. The educational system in the European Union includes education, technology, research, finance and management. Romanian educational centers are a part in this long-term objective and our suggestion is to improve the best management in performance orientation supporting the quality of the persons and not their political connections.

Important changes of the educational system after the collapse of communism has not transformed totally the institutions into modern welfare centers. The Romanian model is in these cases an ambiguous concept and is not based on a culture of consensus between higher institutions, government and social society. We identify some features in supporting the affirmation:

1. The state has an interventionist policy in relation to universities and the cooperation among the actors of the concept is not a general norm of improving excellency.

2. The negotiations are not always centralized and there is not a solidarity in offering the same funds for public or private universities. The last ones are forced to present excellent results due to the early stage of their existence.

3. The educational labor unions are not highly competitive without having a decent rate of growth in sustaining progress.

As concrete issues to solve the problems, Romania needs a shift in educational management brought forth by improving its performance according to EU policies. The influence of political leadership must be stopped, because it is causing Romania to lag behind the international standards of academic quality. The internationalization of higher education is helping in adapting the national market to different cultures and is sustaining long-term modernization. The present is demanding to leave behind many aspects of the traditional teaching methodology (an extended curriculum, outdated classes) and to promote the innovative training. As a solution, innovative training and the evolution to a knowledge intensive society will raise the country from a small performance toward a more average European level of success. Research is also one of the best solutions for the private and public universities to survive and the implementation of the principles of lifelong learning offer solutions to enhance training at tertiary school levels. Personal independence in research is desirable, and scholars must be encouraged in becoming independent persons in relations with the society following the institutional collective welfare. Independence could be associated with the conscious fulfillment of the institutional duties because their engagement is voluntary beyond the institutional arrangements and personal relationships.

The performance must seek the success of the members under the aegis of the institutions. Our recommendation for universities is to offer constant feedback for the scholarly performance of the personnel and to honor the grades of the most dedicated students. Rewarding excellence provides a base for improving the managerial performance under the principles of competence and not following the political and social connections of the individuals.

The Romanian educational system must prove its credibility in order to redefine the performance orientation of the educational national system following the European managerial curricula for higher education. There is a compulsory need for improving two items: 
1. A system capable of offering for alumni full employment after the graduation.

2. An educational system capable of providing equal social rights.

For realizing these two goals, the cooperation between the government and the educational stakeholders must be based on the democratic use of power. Only democracy in education is suitable for the educational outcomes (Biesta, 2015) and is capable of providing explicit suggestions for the ethical and political dimensions of the process in Romania. As main strategy for the improvement of the educational management we can infer that the inequality in the Romanian education system can be transcended only by modernization and the implementation of European funds. The principles of social rights, the educational perspective through time (Cole, 2018) are the best input for a real synergy between government, corporations and students. The economic level of development in any modern education system is interconnected with educational modernization and long-term performance orientation. In the same way the cultural modernization, according to Antikainen (2006) is strongly associated with the decreasing of socio-economic inequalities in education.

The future of the country becomes largely dependent on the interrelation between the major academic players and the corporations in order to manage the capital effectively.

As final remark, in our opinion, future oriented behaviors as planning and constant investments in the future of education are not focused on long term success, rather short-term comfort is appreciated. Even though the country is not among the European leaders in terms of investments, the educational literacy of the population is high, and Romanian students are highly appreciated abroad. There is a need for an increased human orientation in education who will reward the best scholars and professors capable of playing a central role in sustaining the rights and interests of education.

\section{Conclusions}

In this study we presented general variables in the educational process of Romanian universities and some insights about the performance orientated process. Compared to EU-15, performance orientation in the Romanian educational system has been modest in many cases. The act of performance in management is stimulated by a combination of factors relating to the entrepreneurship European spirit with high skilled national educational managers. Constant political and economic transitions did not offering a graduall development of higher education strategies in Romania. In the context of an inefficient educational management, based mostly on political connections, the general performance of the educational system has been sanctioned by the migration of an important number of top students and scholars to universities abroad.

We can infer that education is relatively independent but exists as a strong influence of political power in Romanian society. One of the solutions for the performance is reducing nepotism and cronyism and projecting the democratic values of education into the Eastern European terrain. This aspect can develop a national educational model with equal opportunities for everybody and the educational management will be free from the parties' interest group. South East Europe is having its differences in educational beliefs and attitudes outlined in this article article so as to better understand the performance orientation reality expected of the Romanian high educational system. A solid education based on the European strategy for development needs to be the only launching ramp for the welfare of the state and not the political influence or cronyism as it happens today.

The development of competence-based education and innovative training are necessary for increasing performance in this respect. The full acceptance of Acquis Communautaire will determine the evolution of the educational engagement between Romania and the European Union. The elimination of corruption and clientelism, the development of a privileged partnership with international partners for attracting European funds will increase the Romanian performance inside the Union.

The general tendency in the national media is supporting our assumption that the lack of professionalism from the political elite is vitiating the quality of educational efficiency. The delaying in implementing the reforms combined with bureaucracy and public corruption are obstacles to achieving long-term progress in education.

\section{References}

Antikainen, A. (2006). In Search of the Nordic Model in Education. Scandinavian Journal of Educational Research, 50(3), 229-243. Retrieved March 12, 2019, https:// 10.1080/00313830600743258

Biesta, G.J.J. (2015). Good Education in an Age of Measurement. New York, Routledge. 
Bussines Review. (2015). Retrieved March 15, 2019, from http://business-review.eu/featured/romanian-students-win-fourmedals-two-gold-at-the-european-girls-mathematical-olympiad-60542

Crowther, W. (2010). Introduction: Contemporary Romanian politics. Communist and Post-Communist Studies, 43 (10), 1-5.

Chhokar, S.J., Brodbeck, F. \& House, R.J. (2008). Culture and Leadership Across the World. The GLOBE Book of the InDepth Studies of 25 Societies. London, Tylor and Francis Group.

Gallagher, T. (2009). Romania and the European Union How the weak vanquished the strong. Manchester, Manchester University Press.

Cole, M. (2018). Education, Equality and Human Rights. London, Routledge.

Gasse, Y. \& Tremblay, M. (2011). Entrepreneurial Beliefs and Intentions: A Cross-Cultural Study of University Students in Seven Countries. International journal of business,16(4), 303-314.

Gender Equality Index - Romania. (2017). Retrieved March 12, 2019, from https://eige.europa.eu/publications/genderequality-index-2017-romania

Europa. Eu. (2019). Retrieved March 15, 2019 from

http://ec.europa.eu/eu2020/pdf/COMPLET\%20EN\%20BARROSO\%20\%20\%20007\%20-\%20Europe\%202020\%20$\% 20 \mathrm{EN} \% 20$ version.pdf

European Institute in Romania. (2019). Retrieved March 15, 2019 from http://europedirectbucuresti.ier.ro/wpcontent/uploads/brosura_europa_2020_8mb.pdf

Hofstede, G. \& Hofstede, G.I. (2005). Cultures and organizations. Software of the mind. Intercultural cooperation and its importance for survival. New York, Mc Graw Hill.

House, R.J., Hanges, M., Javidan; M., Dorfman. P.J., Gupta, V. (2004). Culture, Leadership andOrganizations: The GLOBE study of 62 societies. Thousand Oaks CA, Sage.

Ioan, C.A. (2018). Global Education Level Analysis - Part three. Acta Universitatis Danubius. Economica, 14 (7), 117-156.

National Institute of Statistics. (2019). The usually resident population. Retrieved March 12, 2019, from

http://www.insse.ro/cms/sites/default/files/com_presa/com_pdf/poprez_ian2017e.pdf

Ranking web of Universities. (2019). Retrieved March 14, 2019, from

http://www.webometrics.info/en/Ranking_Europe/Central_Eastern_Europe

Pantic, N. (2012). Teacher education reforms between higher education and general education transformations in SouthEastern Europe: reviewing the evidence and scoping the issues. CEPS Journal, 2 (4), 71-90.

Papadimitriou, D. \& Phinnemore, P. (2008). Romania and The European Union. From Marginalisation to Membership? London, Routledge.

Romanian census. (2011). Retrieved March 14, 2019, from http://www.recensamantromania.ro/wpcontent/uploads/2013/07/REZULTATE-DEFINITIVE-RPL_2011.pdf

Romania insider. (2018). Retrieved March 14, 2019, from https://www.romania-insider.com/number-students-drop

Sjovaag, M.M. \& Bergmann, E. (2012). The Study of the European Union from outside: European Integration Studies in Norway and Iceland. Bologna: Societa Editrice il Milano.

Tonnies, F. (2017). Communism, Conformity and Liberties. New York, Routledge.

Tatto, M. T. \& Mincu M. (2009). Reforming Teaching and Learning: Comparative Perspectives in a Global Era. Rotterdam: Sense Publishers.

UAIC. (2019). Retrieved March 15, 2019, from http://www.uaic.ro/en/about-uaic/university/

Webster, C., Silova, I., Moyer, A., \& McAllister, S. (2011). Leading in the age of post-socialist education transformations: Examining sustainability of teacher education reform in Latvia. Journal of Educational Change, 12 (1), 347-370.

Zgaga, P. (2013). Higher education research and higher education policy in South-East Europe. European Journal of Higher Education, 3 (3), 280-294.

Zait, D. (2002). Management intercultural. Bucharest, Economica. 